\title{
Endoscopic treatment of tracheoesophageal fistula: use of stents and endoclips
}

\author{
Thomas Ciecierega ${ }^{1 \#}$, Reem Z. Sharaiha ${ }^{2 \#}$ \\ ${ }^{1}$ Division of Pediatric Gastroenterology and Hepatology, Department of Pediatrics, Weill Cornell Medical College/New York Presbyterian Hospital, \\ New York, NY, USA; ${ }^{2}$ Divison of Gastroenterology and Hepatology, Weill Cornell Medicine, New York, NY, USA \\ Contributions: (I) Conception and design: Both authors; (II) Administrative support: None; (III) Provision of study materials or patients: None; (IV) \\ Collection and assembly of data: None; (V) Data analysis and interpretation: None; (VI) Manuscript writing: Both authors; (VII) Final approval of \\ manuscript: Both authors. \\ \#These authors contributed equally to this work. \\ Correspondence to: Thomas Ciecierega, MD. New York Presbyterian, Weill Cornell medical College, New York, NY, USA. Email: ciecierega@gmail.com; \\ Reem Z. Sharaiha, MD. Division of Gastroenterology and Hepatology, Weill Cornell Medicine, New York, NY, USA. Email: rzs9001@med.cornell.edu.
}

\begin{abstract}
Tracheoesophageal fistula (TEF) is a rare gastrointestinal pathology of abnormal connection or passage between the esophagus and the trachea. Most frequently, TEF is a primary (congenital) in origin and most often associated with the esophageal atresia (EA). TEF can develop as a consequence of another disease, syndrome or condition (secondary) such as infectious esophagitis, trauma, foreign body or neoplasm. Regardless of the etiology, TEF represents treatment challenge. TEF can present with wide ranging symptoms including cough, choking, gagging, poor growth and occasionally with severe complications of pulmonary aspiration. The diagnostic test of choice remains radiographic imaging. Contrast studies can usually identify majority of TEFs including their anatomical characteristics such as size, location and communication. Sometimes additional imaging in form of CT-scan or magnetic resonance imaging (MRI) or direct bronchoscopy/endoscopy need to perform to identify TEF with unusual anatomical characteristics. Surgical correction has been the mainstay of TEF repair, especially with an advent of endoscopic and robotic surgery. Surgical closure effectiveness and decreased adverse events have continued to advance over the past few decades. However, new endoscopic interventions including esophageal stenting and clipping have emerged as supplemental or alternative options. They are safe and effective, minimally invasive treatment options with usually few adverse events. The endoscopic treatment might also be preferred in certain patients who cannot undergo surgery safely. Although, much more common in adult population, esophageal stenting or clipping is becoming more popular in pediatrics.
\end{abstract}

Keywords: Tracheoesophageal fistula (TEF); esophageal atresia (EA); endoscopy; stent; endoclip

Received: 11 September 2020; Accepted: 16 October 2020; Published: 25 August 2022.

doi: $10.21037 /$ ccts-20-155

View this article at: http://dx.doi.org/10.21037/ccts-20-155

\section{Introduction}

Tracheoesophageal fistula (TEF) is an abnormal communication between esophagus and trachea. Isolated TEF is rare, frequently associated with other structural abnormalities, most commonly esophageal atresia (EA).

TEF is diagnosed most frequently through fluoroscopic imaging, although endoscopy and bronchoscopy are sometimes used to help identify the abnormal connection.
The mainstay of tracheoesophageal treatment has been surgical correction, although endoscopic approaches have been slowly gaining increasing acceptance as treatment modalities.

\section{TEF}

TEF is a rare gastrointestinal pathology of abnormal connection or passage between the esophagus and the 
Table 1 Causes of TEF not associated with EA

Non-malignant
Foreign body (button battery)
Trauma (prolonged intubation, penetrating, blunt or crush
injuries)
Infections (syphilis, tuberculosis, candida, histoplasmosis,
CMV, herpes, HIV)
Previous thoracic surgery
Caustic ingestions/inhalation burns
Latrogenic causes
Endoscopy, esophageal ultrasound/echocardiography, chest
tubes
Malignancies
Lung cancer
Esophageal cancer

TEF, tracheoesophageal fistula; EA, esophageal atresia; CMV, cytomegalovirus.

trachea. Most frequently, TEF is a primary (congenital) in origin and most often it is associated with presence of the EA. EA which is almost always associated with TEF is the most common gastrointestinal malformation occurring in 1/2,400-4,500 live births (1). Five distinctive types of EA exist with Type $\mathrm{C}$ (EA with distal TEF) representing around $87 \%$ of all the cases.

Although TEF is most frequently occurring in infancy as part of congenital EA, various causes of late onset TEF (secondary) have been described in literature (Table 1) (2-7). TEF can develop as a consequence of another disease, syndrome or condition such as infectious esophagitis, trauma, foreign body or neoplasm.

TEF typically presents with wide ranging symptoms including cough, choking, gagging, poor growth and occasionally severe complications of aspiration leading to respiratory compromise, pneumonias and chronic lung damage, depending on its anatomical and physical characteristics.

Diagnostic test of choice is radiographic imaging. Although simple radiograph of the chest can diagnose TEF, CT-scan and magnetic resonance imaging (MRI) have also been used to identify an isolated TEF. An antenatal ultrasound can identify polyhydramnios and distended proximal, blind esophageal pouch, indicative of congenital TEF (8). However, the gold standard test for TEF identification has been fluoroscopic radiography. Contrast studies usually identify up to $70 \%$ of lesions including their anatomical position, communication, length, width and orientation $(6,7,9)$.

Regardless of its underlying pathology, TEF must be repaired to prevent long lasting complications including possible death. TEF can, however, present challenging to repair. Although surgical correction has been the mainstay of TEF repair, especially with an advent of endoscopic and robotic surgery, new endoscopic modalities have emerged as supplemental or alternative options. Most common therapeutic endoscopic modalities include stenting, tissue glue, and clipping.

\section{Treatment options of TEF: endoclips and stents}

Although surgically corrected TEF remains the gold standard of treatment, advances in therapeutic endoscopy allowed for introduction of esophageal stenting and endoclips as adjuncts to surgery. The choice of either surgery or endoscopic treatment of TEF also depends on their etiology, size, anatomy and patient's comorbidities. In certain clinical settings, some patients cannot undergo safely a surgical repair because of their health or because TEF which may be a part of a non-operable advanced malignancy. Endoscopic closure of the TEF is high with reported success rate ranging between $87 \%$ and $100 \%$ (10). It can be an attractive option in secondary and recurrent fistulas.

\section{Stents}

There are multiple types of stents available on the market today. Each stent will have its benefits and drawbacks which need to be considered before its placement. However, universally, several common complications are shared between all the stents including esophageal obstruction, migration, perforation, infection, pain and bleeding.

In the past, rigid, often plastic stents were used but were prone to high rate of adverse events and morbidities (11). Most recently, they were replaced by stents made from metal alloy compounds and polymers. Additionally, a new class of self-expanding plastic stents (SEPS) and selfexpanding metal stents (SEMS) became available, although not approved by Food and Drug Administration (FDA) for benign indications. Finally, the latest are the biodegradable stents which are manufactured from woven polydioxanone monofilaments and start to dissolve after 11 weeks from time of placement (12). 
Each stent has its advantages including specific radian forces to optimize placement and minimize migration, polymer coatings to reduce esophageal tissue overgrowth and radiographic markers for guidance of precise placement.

Clinical success ranges between $60-80 \%$ depending on the timing of stent placement $(13,14)$. Complications of stent placement can be early (within 4 weeks of stent placement) or late (beyond 4 weeks of stent placement). Early complications have been reported in up to third of patients and stent migration is the most common complication in both, early and late complications, occurring in $7-75 \%(15,16)$. Stent migration can be prevented with endoscopic suturing or clipping and this has been associated with improved clinical outcomes (17).

\section{Endoclips}

Endoscopic clips have been the mainstay for control of gastrointestinal bleeding for the past few decades. Most recently, their use in treatment of TEF has been increasing. Endoclips can be subdivided into two groups depending on their mode of deployment. They can be either over the scope (OTS) or through the scope (TTS). They come in varying shapes and sizes, some with ability to rotate and allowing multiple openings and closures. Similarly to stents, choice of endoclip (size, shape, deployment method) depends on physician performing procedure, type and location of TEF.

Endoclips have been used successfully in TEF closures including infants and pediatric patients (18-20). Chavez et al reported overall success rate for fistula closure using the OTS clip in $45 \%$ (21).

In addition, combining other endoscopic procedures with endoclipping has been reported in the literature. Van Bodegraven et al. (22) reported use of argon plasma coagulation to induce inflammation and improve tissue healing/adherence before clipping to successfully close the esophagopleural fistula.

Complications from endoclip placement are similar but with less frequency than to those of stents. Endoclips are generally well tolerated and safe with only few reports in the literature of serious complications. Some of these complications include premature detachment, cause perforation, obstruction, infection and bleeding.

Yoon et al. (23) described successful treatment of recurrent congenital TEF with Histoacryl glue. Glue can be an alternative method of TEF treatment and as a tissue adhesive, allows for relatively non-invasive treatment approach. Detachment, occlusion and the need for repeat treatments are some of the possible adverse events.

\section{Conclusions}

TEF is an abnormal communication between esophagus and trachea. It usually presents in neonatal period as part of EA abnormality. Endoscopy/bronchoscopy and radiographic imaging have been at the center of the diagnosis of TEF. Although surgical correction remains the most common approach in correcting TEF, therapeutic endoscopic stenting and clipping have been most recently gaining traction as treatment modalities, especially in complicated and medically unstable patients. With ongoing advent of robotics and miniaturization, new treatment options in form of remotely operated microscopic drones might emerge soon. Meanwhile, stenting and endoclipping is being advanced through therapeutic endoscopy in adult and pediatric settings.

\section{Acknowledgments}

Funding: None.

\section{Footnote}

Provenance and Peer Review: This article was commissioned by the Guest Editor (Tutku Soyer) for the series "Tracheoesophageal Fistula" published in Current Challenges in Thoracic Surgery. The article has undergone external peer review.

Conflicts of Interest: Both authors have completed the ICMJE uniform disclosure form (available at https://ccts. amegroups.com/article/view/10.21037/ccts-20-155/coif). The series "Tracheoesophageal Fistula" was commissioned by the editorial office without any funding or sponsorship. RZS reports grants and others from Boston Scientific, Cook and Olympus, outside the submitted work. The authors have no other conflicts of interest to declare.

Ethical Statement: The authors are accountable for all aspects of the work in ensuring that questions related to the accuracy or integrity of any part of the work are appropriately investigated and resolved.

Open Access Statement: This is an Open Access article distributed in accordance with the Creative Commons 
Attribution-NonCommercial-NoDerivs 4.0 International License (CC BY-NC-ND 4.0), which permits the noncommercial replication and distribution of the article with the strict proviso that no changes or edits are made and the original work is properly cited (including links to both the formal publication through the relevant DOI and the license). See: https://creativecommons.org/licenses/by-nc-nd/4.0/.

\section{References}

1. Shaw-Smith C. Oesophageal atresia, tracheo-oesophageal fistula, and the VACTERL association: review of genetics and epidemiology. J Med Genet 2006;43:545-54.

2. Reed MF, Mathisen DJ. Tracheoesophageal fistula. Chest Surg Clin N Am 2003;13:271-89.

3. Chen YH, Li SH, Chiu YC, et al. Comparative study of esophageal stent and feeding gastrostomy/jejunostomy for tracheoesophageal fistula caused by esophageal squamous cell carcinoma. PLoS One 2012;7:e42766.

4. Balazs A, Kupcsulik PK, Galambos Z. Esophagorespiratory fistulas of tumorous origin. Non-operative management of 264 cases in a 20-year period. Eur J Cardiothorac Surg 2008;34:1103.

5. Rodriguez AN, Diaz-Jimenez JP. Malignant respiratorydigestive fistulas. Curr Opin Pulm Med 2010;16:329.

6. Couraud L, Ballester MJ, Delaisement C. Acquired tracheoesophageal fistula and its management. Semin Thorac Cardiovasc Surg 1996;8:392-9.

7. Grillo HC. Acquired tracheoesophageal fistula and bronchoesophageal fistula. In: Surgery of the Trachea and Bronchi. New York: BC Dekker Inc 2003:341-56.

8. Centini G, Rosignoli L, Kenanidis A, et al. Prenatal diagnosis of esophageal atresia with the pouch sign. Ultrasound Obstet Gynecol 2003;21:494-7.

9. Bartels HE, Stein HJ, Siewert JR. Tracheobronchial lesions following oesophagectomy: prevalence, predisposing factors and outcome, Br J Surg 1998;85:403-6.

10. Chawla RK, Madan A, Chawla K. Tracheo-esophageal fistula: Successful palliation after failed esophageal stent. Lung India 2012;29:289-92.

11. Parker CH, Peura DA. Palliative treatment of esophageal carcinoma using esophageal dilation and prosthesis. Gastroenterol Clin North Am 1991;20:717-29.

12. Sigounas DE, Siddhi S, Plevris JN. Biodegradable esophageal stents in benign and malignant strictures - a single center experience. Endosc Int Open 2016;4:E618-23.

13. Silon B, Siddiqui AA, Taylor LJ, et al. Endoscopic Management of Esophagorespiratory Fistulas: A
Multicenter Retrospective Study of Techniques and Outcomes. Dig Dis Sci 2017;62:424-31.

14. Sharaiha RZ, Kumta NA, DeFilippis EM, et al. A Large Multicenter Experience With Endoscopic Suturing for Management of Gastrointestinal Defects and Stent Anchorage in 122 Patients: A Retrospective Review. J Clin Gastroenterol 2016;50:388-92.

15. Sharma P, Kozarek R. Practice Parameters Committee of American College of Gastroenterology. Role of esophageal stents in benign and malignant diseases. Am J Gastroenterol 2010;105:258-73.

16. Johnson E, Enden T, Noreng HJ, et al. Survival and complications after insertion of self-expandable metal stents for malignant oesophageal stenosis. Scand J Gastroenterol 2006;41:252-6.

17. Ngamruengphong S, Sharaiha RZ, Sethi A, et al. Endoscopic suturing for the prevention of stent migration in benign upper gastrointestinal conditions: a comparative multicenter study. Endoscopy 2016;48:802-8.

18. Benatta MA, Benaired A, Khelifaoui A. Endoscopic stenting and clipping for anastomotic stricture and persistent tracheoesophageal fistula after surgical repair of esophageal atresia in an infant. Case Rep Med 2014;2014:738981.

19. Voermans RP, Le Moine O, von Renteln D, et al. Efficacy of endoscopic closure of acute perforations of the gastrointestinal tract. Clin Gastroenterol Hepatol 2012;10:603-8.

20. Zolotarevsky E, Kwon Y, Bains M, et al.

Esophagobronchial fistula closure using a novel endoscopic over-the-scope-clip. Ann Thorac Surg 2012;94:e69-70.

21. Chavez YH, Kratt T, Law JK, et al. A Large International Multicenter Experience With an Over-the- Scope Clipping Device for Endoscopic Management of Gastrointestinal Perforations, Fistulae, and Leaks in 188 Patients. Gastroint Endos 2013;77:AB148.

22. van Bodegraven AA, Kuipers EJ, Bonenkamp HJ, et al. Esophagopleural fistula treated endoscopically with argon beam electrocoagulation and clips. Gastrointest Endosc 1999;50:407-9.

23. Yoon JH, Lee HL, Lee OY, et al. Endoscopic treatment of recurrent congenital tracheoesophageal fistula with Histoacryl glue via the esophagus. Gastrointest Endosc 2009;69:1394-6.

doi: $10.21037 /$ ccts-20-155

Cite this article as: Ciecierega T, Sharaiha RZ. Endoscopic treatment of tracheoesophageal fistula: use of stents and endoclips. Curr Chall Thorac Surg 2022;4:24. 